\title{
Frontonasal dysplasia-severe microphthalmia-severe facial clefting syndrome
}

INSERM

\section{Source}

INSERM. (1999). Orphanet: an online rare disease and orphan drug data base. Frontonasal dysplasia-severe microphthalmia-severe facial clefting syndrome. ORPHA:306542

Frontonasal dysplasia-severe microphthalmia-severe facial clefting syndrome is a rare, genetic, orofacial clefting malformation syndrome characterized by severe frontonasal dysplasia with complete cleft palate, facial cleft, extreme microphtalmia and hypertelorism, frequently associated with eyelid colobomata, sparse or absent eyelashes/eyebrows, wide nasal bridge with hypoplastic alae nasi, low-set, posteriorly rotated ears and caudal appendage in the sacral region. 